\title{
The Strategic Implications of Switching Costs Under Customized Pricing
}

\author{
Yuxin Chen • Pradeep Bhardwaj • \\ Sridhar Balasubramanian
}

Published online: 23 May 2014

(C) Springer Science+Business Media New York 2014

\begin{abstract}
We analyze how consumer switching costs affect firm pricing and profits under competition. In our model, duopolists who implement customized pricing compete over two periods. Departing from the literature and reflecting the notion of consumers as limited processors of information in cluttered environments, we assume that consumers may or may not engage in price comparisons every period - this depends on the price offered by the firm they can potentially switch to. When the offered price - the bait-is sufficiently low, consumers engage in price comparisons and choose a firm to patronize. In contrast to existing findings, we first demonstrate that switching costs may reduce even singleperiod profits. We then demarcate conditions under which total (two-period) firm profits increase or decrease with switching costs or are independent of such costs. Finally, we study how strategic consumers affect profits. In the literature, such forward-looking consumers are wary of being baited by a low price only to be locked-in later by high switching costs. Therefore, price sensitivity is lower when consumers are strategic - this increases firm profits. In contrast, we demonstrate that firm profits can reduce when consumers are strategic. Our findings shed light on how competing firms should manage switching costs under customized pricing.
\end{abstract}

\footnotetext{
Y. Chen

NYU Shanghai, Shanghai, China

e-mail: yc18@nyu.edu

P. Bhardwaj $(\bowtie)$

College of Business Administration, University of Central Florida,

Orlando, FL 32816, USA

e-mail: pbhardwaj@bus.ucf.edu

S. Balasubramanian

Kenan-Flagler Business School, UNC, Chapel Hill, Chapel Hill, NC, USA

e-mail: Sridhar_Balasubramanian@unc.edu
}

Keywords Switching costs $\cdot$ Customized pricing $\cdot$ Game theory $\cdot$ Lock-in

\section{Introduction}

Consumers can incur a switching cost if they shift to a competitor [1-3]. Switching costs can be influenced by (a) marketing initiatives such as loyalty programs, (b) a familiarity with the current firm and a hesitation to venture into the unknown, or (c) psychological factors such as an endowment effect which can make consumers reluctant to part with what they already possess. The ability of switching costs to moderate competition has frequently been studied by business and policy researchers. Across industries, managers can implement initiatives such as loyalty discounts that can quickly impact switching costs and switching behavior. Consequently, switching costs are also of direct interest to managers.

In this paper, we examine how switching costs affect outcomes in a duopoly where firms engaging in customized pricing charge distinct prices to their own customers and to the competitor's customers. The existing literature on switching costs has focused on scenarios where the firm charges a single "market" price. Further, consumer price search and comparison processes are exogenously specified in the existing literature. In contrast, we endogenize the price comparison process by allowing consumers to choose to engage in price comparison and switching as a function of the price offered by a competing firm.

Our findings yield new insights into the strategic implications of switching costs. For example, the literature is generally consistent on the notion that switching costs increase profits that derive from short-term (single period) competition. Existing debate on the implications of switching costs for profitability focuses on the long-term effects of such costs. In contrast, we demonstrate that increasing switching costs can decrease firm 
profits even when firms compete over a single period. We also demarcate conditions under which firm profits can increase or decrease as a function of switching costs under customized pricing. We show that the drivers of this nonlinear effect are different from those in a noncustomized pricing environment (e.g., [4]). Our findings also shed light on how forward-thinking (or strategic) consumers affect firm profits. In the literature, strategic consumers are wary about being exploited by firms in the future after they are locked-in by switching costs - this makes them less sensitive to being baited by low prices in the short run. As demonstrated in the literature, this reduces consumer sensitivity to prices in the short run and increases profits. We demonstrate instead that these profits can be lower when consumers are strategic.

Background Existing analytical work has examined how consumer switching costs moderate competitive interactions [5-7]. In early work, von Weizsacker [8] demonstrates that, when faced with switching costs, consumers weigh future uncertainties about their preferences more strongly than the present advantages of a product because they want to avoid being locked-in with the "wrong" seller. In his model, firms are constrained to charge the same price in each period. As a result, firms compete more intensely to attract consumers and the market with switching costs is more competitive than one without.

Relaxing the assumption of constant intertemporal pricing, Klemperer [9] demonstrates that high switching costs can lead to monopoly power over their locked-in consumers, thereby increasing profits. However, this also increases competition between firms to capture consumers in earlier periods in order to leverage the switching costs in the future. If a higher (future) market share hurts a firm by making the competitor more aggressive, then upfront competition can be reduced in the presence of switching costs [10]. Alternatively, if consumers are forward-looking, they can foresee that a low initial price is a bait and that the firm will extract future surplus on account of switching costs. Correspondingly, upfront competition between firms is again lessened (compared to a market without switching costs) because strategic consumers are less price sensitive in early periods. In either of these cases, switching costs unambiguously increase profits [1]. Asymmetries across firms can moderate the implications of switching costs as well. For example, larger telecom firms gained when cell phone number portability reduced switching costs because their discounts for "in-network" calling were more appealing to consumers [11].

Summarizing the literature, Fudenberg and Villas-Boas [12] delineate three mechanisms through which behaviorbased price discrimination and switching costs influence profits when duopolists compete across two periods. First, firm profits in period 2 increase because consumers are reluctant to switch - this reduces price sensitivity and supports higher equilibrium prices and profits. Second, forwardlooking consumers are wary of facing higher prices on account of switching costs in period 2-this makes them less susceptible to being enticed by lower prices in period 1 , encouraging higher upfront prices that increase period 1 profits. Finally, in order to leverage switching costs in period 2 , firms seek to maximize their market share in period 1 - this induces lower prices and reduces upfront profits. ${ }^{12}$

The mix of loyal consumers (or those with high switching costs) and switching consumers (those with low switching costs) in a market can also influence competition [18, 19]. When duopolists compete across multiple periods in a market with loyal and switcher segments (but with no intertemporal consumer loyalty effects), the equilibrium may involve mixed pricing strategies [18]. In this scenario, the occurrence of prices below the maximum can be interpreted as discounts from the regular (maximum) price. Likewise, the competitive equilibrium will be influenced by the firm's ability to differentially target its own customers and competitors' customers. In that case, the degree of correlation in consumer brand preferences across time can influence the nature of competition. Specifically, when duopolists can commit to future prices and temporal preference dependence is low, the firms focus on keeping their own customers by rewarding loyalty-this induces customers to stay rather than defect to the competitor; however, each firm focuses on attracting the competitor's customers when preference dependence is high [20].

The general argument in the literature is that switching costs make markets less competitive. However, a simulation based on an empirical analysis of choice data for frequently purchased goods suggests that for intermediate levels of switching costs, markets become more competitive as switching costs increase [21]. The proposed model allows for differentiated products and imperfect lock-in in an infinite horizon setting. Intuitively, increasing switching costs in this scenario provides greater incentives to lower prices and capture new consumers than to harvest profits from consumers who already patronize the firm (current customers). In responding to these findings, Shin and Sudhir [4] develop a

\footnotetext{
${ }^{1}$ If switching cost is information that is private to consumers, those consumers may change suppliers just to establish a reputation and receive the lower price offered to switchers [7]. When products are perfect substitutes, firms may alternate between selling to all of the new and all of the old consumers in overlapping generation models [13, 14]. For a model of overlapping generations of consumers with differential pricing for existing consumers, see Villas-Boas [15], and for an analysis of price cycles in markets where new consumers enter during each period, see Villas-Boas [16]. For an analysis of how loyalty programs may increase or decrease firm profits, depending on how they differentially affect heavy and light use, see Kim et al. [17].

${ }^{2}$ A monopolist may be able to enhance profits if she can credibly ignore information about forward-looking consumers. Such consumers are wary about being locked-in and charged higher prices in the future - therefore, they exhibit a reduced willingness to pay if they believe the monopolist possesses information that enables this outcome [16].
} 
two-period analytical model where consumer preferences are drawn from a random distribution in each period. They demonstrate that an increase in switching costs can first increase competition and reduce profits (at lower levels of switching cost) and then moderate competition (at higher levels of switching cost). They suggest that in a finite-period model, preference heterogeneity and dynamic consumer-level preferences are both necessary for this U-shaped effect to hold.

Likewise, switching costs can be analyzed in terms of their effects on the incentives of firms to invest in creating versus harvesting that market share [22]. Cabral argues that the investment effect negatively influences the prices of all competitors, whereas the harvesting incentive can increase (reduce) the prices of firms with a larger (smaller) market share. The average market price can increase in this scenario.

A parallel stream of literature has examined the implications of targeting individual consumers or groups of consumers. Such targeting may reduce profits in a competitive environment on account of interfirm strategic effects [12, 23]. Competing targeting initiatives may neutralize each other, leaving firms worse off than if neither of them engaged in targeted marketing. The occurrence of such a prisoner's dilemma in the context of individual marketing initiatives has been highlighted in the literature (e.g., [24, 25]).

In general, the effectiveness of targeting initiatives depends on the balance between the increased consumer surplus extraction that these initiatives facilitate and the more intense competition that they foster [26]. Interestingly, some of the positive implications of targeted marketing are restored if (a) the targeting is inefficient (or less-than-perfect) or (b) some market asymmetries are introduced. For example, individual marketing in a competitive context can be profitable when a firm can only imperfectly discriminate between loyal consumers and switchers - this ensures that some of the incorrectly identified potential switchers receive a higher price because the firm does not expect them to switch. This reduces the pressure on the competitor to aggressively lower prices to attract those potential switchers, thereby leading to higher equilibrium prices and profits [27]. Similarly, when firms are asymmetric, targeted promotions do not offset each other exactly and the larger firm could gain market share [28]. In some situations, an asymmetric outcome where one firm launches a loyalty program and the competitor responds with price discounts may emerge in equilibrium [29].

Contribution Our work lies at the intersection of, and links, the switching cost and customized pricing literatures. The customized pricing literature has examined the implications of the growing capability of firms to design marketing initiatives at the level of the individual consumer (e.g., [26, 27, 30]). In keeping with precedence, we assume that firms have the capability to engage in customized pricing in this paper.
We present a game-theoretic model of competition in a duopoly. The firms compete over two periods, and each firm offers a distinct price to its existing customer and to that of its competitor. Each consumer has a "preferred" firm. A consumer who is resident with a nonpreferred firm (i.e., who purchased from the nonpreferred firm in the first period) always engages in price comparisons to evaluate switching to the preferred firm. In contrast, a consumer resident with a preferred firm (i.e., who purchased from the preferred firm in the first period) will compare prices and evaluate switching only when the price offered by the competitor is relatively low. This captures the inertia that consumers exhibit when they are satisfied with their current firm. Such consumers may require an attractive bait to encourage them to evaluate the benefits and costs of switching. These assumptions capture some of the randomness that is inherent in switching behavior and the inability of the firms to accurately gauge a specific consumer's propensity to switch - these are significant practical challenges faced by marketing managers in the field. Consumers who do switch incur switching costs. On the supply side, the firms maximize total two-period profits. Therefore, in period 1 , each firm sets prices for the consumer who prefers its product and the consumer who prefers the competitor's product after analyzing the implications of these pricing decisions for switching behavior and period 2 profits as well.

We show that, in contrast to existing findings, higher switching costs can reduce profits even when the firms compete over a single period. We demonstrate that, under customized pricing, firms may decide to compensate competitors' customers for higher switching costs to induce them to switch. This reduces profits. In contrast, in the existing literature, the effects of switching costs when firms compete over a single period are similar to those of transportation costs in the classic linear city model [31]—increasing switching costs makes consumers "sticky," thereby reducing price sensitivity and increasing firm profits.

Next, we examine how switching costs affect profitability in a two-period setting. When switching costs are low, we show that total profits of firms decrease as switching costs increase. Under some conditions, firm profits in each period decrease with switching costs. In contrast, when switching costs are sufficiently large, each firm's total profit is either independent of, or increasing in, switching costs. Our findings yield a nuanced understanding of how switching costs affect profits and reconcile results in the literature.

We also examine how the effect of switching costs changes when consumers are forward-looking. In the literature, upfront competition between firms is lessened when consumers are forward-looking (e.g., [1]). The intuition is that these consumers are sensitive to being drawn in by a low price offered by a firm, only to lose substantial surplus in the future after being locked-in by switching costs. Therefore, strategic consumers are unlikely to be enticed by low initial prices. This 
reduces the intensity of price competition and increases total firm profits. We demonstrate that, when switching costs are low, firm profits when consumers are strategic may be lower than when they are not.

The basic model and analysis are introduced in Section 2. The implications of our findings are discussed and future avenues for research are demarcated in Section 3. The analysis involves the demarcation of parametric conditions. Accordingly, to maintain continuity and logical coherence, we present the analysis in the main body of the text rather than in a separate appendix. However, to enhance exposition and understanding, we intersperse the analysis with commentaries that highlight the underlying intuitions.

\section{Model and Analysis}

We model a duopoly where two symmetric firms compete over two periods. Each firm offers a distinct price to each consumer. There are two consumers, with differential preferences. Consumer 1 prefers firm 1 and has a reservation price of $1+h$ for its product and a reservation price of 1 for firm 2's product. Likewise, consumer 2 prefers firm 2 and has a reservation price of $1+h$ for its product and a reservation price of 1 for firm 1's product. Each consumer buys at most one product unit per period. Consistent with the existing literature on customized pricing, the key competitive forces are captured under the simplified assumption that the demand side comprises just these two "prototypical" consumers.

A consumer who switches firms at the outset of the second period incurs switching costs of $\gamma$. The marginal cost of each firm is normalized to zero. Each firm maximizes its total, two-period profit with a discount factor of one. We model both myopic and strategic consumer behavior. Myopic consumers consider the utility only from consumption in the current period when making a purchase decision. In contrast, strategic consumers also take into account the consumer surplus implications related to the second period when they buy in the first period. We assume that the discount factor for the strategic consumers is one.

Our model of consumer switching is anchored in a behavioral perspective of the willingness of consumers to engage in price search and comparison. Consumers, like all humans, have limited information-processing capabilities. Theories of information processing and selective attention demarcate two domains of stimulus processing (e.g., [32-34]). The firstDomain $\mathrm{A}$ - has been variously labeled as nonconscious, automatic, peripheral, and preattentive, whereas the second - Domain B - has been labeled as conscious, controlled, attentive, and central. Domain A, which offers a large capacity and is passive, is responsible for the preliminary encoding of environmental stimuli. Domain B is of smaller capacity and controls the further processing of information, including the degree of selective attention that is directed towards specific stimuli.

Our model of information processing derives from a direct application of these established theoretical principles to price stimuli in the environment. The price paid by consumers to the firms that they currently patronize may be encoded in the memory of the consumer and can potentially be recalled by the consumer for further processing. Alternatively, consumers can perform additional search to confirm the prices they currently pay. Consumers will also have some broad idea of what comprises a "good" price in the market.

When a consumer encounters a price stimulus from the competing firm, that stimulus is first encoded in Domain A. In order for the price information to be processed further, though, Domain B must decide the level of selective attention that must be paid to the stimulus, after which elementary information processes (EIPs) related to comparing prices offered by the firms can be invoked. Consumers are less likely to engage in further processing if they are locked-in by high switching costs and if the price offered by the competitor is perceived to be high. ${ }^{3}$ This captures the notion that consumers are unlikely to engage in a continuous evaluation of the benefits of switching from one firm to another. Rather, they are more likely to respond to a stimulus in the environment that signals that switching may potentially be beneficial to them. In that case, additional EIPs are invoked. The price the consumer is currently paying is recalled from memory or is established after additional search, the switching cost is more accurately estimated, and switching decision is comprehensively evaluated. To capture these arguments, and in contrast to the existing literature, we endogenize the decision to engage in detailed price comparison based on the preliminary assessment of whether such effort is worthwhile.

Specifically, we assume that a consumer who bought from firm $i(i=1,2)$ in period 1 evaluates whether to switch with probability $z=z\left(p_{3-i}, \gamma\right)$, where $p$ is the price offered to the consumer by that competitor. We assume that $z=a-b\left(p_{3-i}+\gamma\right)$ if firm $i$ is the consumer's preferred firm and $z=1$, otherwise. We define $a(0 \leq a \leq 1)$ as the absolute (price-independent) likelihood of switching evaluation and $b(b \geq 0)$ as the consumer sensitivity to the total cost of switching (represented by the sum of the price charged and the switching cost). We also assume $a \geq b$ to ensure that $0 \leq z \leq 1$ in equilibrium for $0 \leq \gamma \leq 1$. In contrast to the prior literature that has implicitly assumed that consumers are capable of reacting to, and willing to fully process, every price stimulus they encounter, our model assumes a more practical viewpoint of consumers as limited

\footnotetext{
${ }_{3}^{3}$ For example, consider a consumer who obtains substantial discounts from an insurance provider because she has multiple insurance accounts covering the automobile, the home, and health and life with that provider. On account of the high switching costs, this consumer will be less likely to fully process and react to an offer of automobile insurance from a competitor.
} 
capacity information processors who react selectively to the more appealing stimuli in the environment. Specifically, we depart from the notion that consumers pay attention to all price signals sent by competing firms. In a cluttered world, we assume that consumers will superficially scan the environment for all stimuli, but only take up those stimuli that are sufficiently meaningful and promising as inputs for further processing and decision-making. This completes the setup of the model.

Before proceeding further, it is appropriate to link our model to real-life markets to demarcate the specific domains where our modeling approach may be particularly appropriate. As noted earlier, one of the contributions of our works relates to the examination of switching costs under customized pricing. To implement such pricing well, the firm must typically possess information related to choice at an individual consumer level and some information that might serve as a credible signal of switching costs. Therefore, our model would fit less well with markets where segmented pricing is the general norm - many markets for consumer-packaged goods fall into this category. On the other hand, companies in the credit card service, online stock brokerage service, and home security service industries - to name just a few - typically possess individual-level consumer information on choices and historical consumption patterns. Not surprisingly, in these markets, prices offered frequently vary across "own" and competitor's customers, with the latter typically being offered a "sweet deal" to switch (also see [20]). Our model fits well with such markets.

We solve the game using backward induction. Accordingly, we first analyze the second period of the game, focusing throughout on pure strategy equilibria.

\subsection{Single (Second)-Period Analysis}

Assume that a consumer purchased from firm $i$ in period 1 . We denote prices and other variables related to a consumer that prefers (does not prefer) a firm with the subscript $P(\mathrm{NP})$. We analyze the following cases.

Case 1: Firm $i$ is the consumer's preferred firm.

Let the price offered by the firm $i$ to the consumer who prefers it and who purchased from it in period 1 be $p_{P}$ and the price offered by the competitor to the same consumer be $p_{\mathrm{NP}}$. There are two possible pure strategy equilibria in $\left(p_{B} p_{\mathrm{NP}}\right)$ depending on level of switching costs $(\gamma)$. In the first (sub-case 1.1 below), the consumer who is with the preferred firm never switches to the competitor. In the second outcome (sub-case 1.2 below), there is a positive probability of such switching.

Sub-case 1.1: In this equilibrium, the firm attempting to retain the consumer that prefers it charges a price $p_{P}=h+$ $\gamma$, and the competitor prices at marginal cost: $p_{\mathrm{NP}}=0$. At these prices, no switching will occur because each firm offers the consumer a net utility of $1-\gamma$. The singleperiod profits of the firms are as follows:

$\pi_{P}^{*}=h+\gamma \quad$ and $\quad \pi_{\mathrm{NP}}^{*}=0$

If each consumer purchases from her preferred firm in period 1, the total profits of each firm from the two consumers in period 2 , which increase in both differential utility $h$ and switching cost $\gamma$, are

$\pi^{*}=\pi_{P}^{*}+\pi_{\mathrm{NP}}^{*}=h+\gamma$

To ensure that $p_{P}=h+\gamma$ and $p_{\mathrm{NP}}=0$ comprise an equilibrium, neither firm should have an incentive to deviate. Firm $j$ clearly has no incentive to deviate from $p_{\mathrm{NP}}=0$ because its profits cannot be higher than zero from any deviation. The profits of firm $i$ will decrease if it lowers price from $p_{P}=h+\gamma$, but it could potentially charge a higher price. Note that the probability that the consumer considers switching is $z(0, \gamma)=a-b \gamma$. Therefore, the highest possible profits the firm can make from a deviation is $(1+h)[1-z(0, \gamma)]$, where $p_{P}=1+h$ is the maximum price that the firm could charge its preferred consumer-one that leaves the consumer with zero surplus. To prevent this deviation, it must be that $h+\gamma>[1-(a-b \gamma)](1+h)$ or

$\gamma>\frac{1-a-a h}{1-b-b h}$

Commentary: In this sub-case, each firm leverages the high switching costs to create a local monopoly with respect to its preferred consumer. The consumer has no incentive to switch to the competitor even if she compared prices across firms. The profits the firm obtains from its preferred consumer increase in both the preference of the consumer for the firm $(h)$ and switching costs $(\gamma)$. Note that the threshold for $\gamma$ (Eq. 3) is decreasing in $a$ and increasing in $b$. Intuitively, when the absolute likelihood of making a price comparison towards evaluating a switch to the competitor is high (i.e., $a$ is high), the firm finds it less appealing to price at $p_{P}=1+h$ and risk the likelihood of the consumer switching to the competitor. Therefore, this (single-period) equilibrium holds even for lower levels of switching costs. In contrast, when consumer sensitivity to the total cost of switching $(b)$ is high, the firm finds it more appealing to deviate to pricing at $p_{P}=1+h$ because the consumer is less likely to make a price comparison and switch. 
Therefore, when $b$ is high, this equilibrium holds only above a high switching cost threshold.

Sub-case 1.2: The second possible pure strategy equilibrium is when firm 1 prices to its resident consumer at the highest possible price of $p_{P}^{*}=1+h$, above which the consumer obtains negative utility. The competitor firm sets price to maximize expected profits: $p_{N P}^{*}=\arg \max [z$ $\left.\left(p_{N P}, \gamma\right) p_{\mathrm{NP}}\right]=\arg \max p_{\mathrm{NP}}\left(a-b p_{\mathrm{NP}}-b \gamma\right)$. From the first order condition, we obtain $p_{\mathrm{NP}}^{*}=\frac{a-b \gamma}{2 b}$. Substituting for $p_{\mathrm{NP}}^{*}$ in the expression for $z$, we obtain the likelihood of the consumer switching: $z\left(p_{\mathrm{NP}}^{*}, \gamma\right)=\frac{a-b \gamma}{2}$. The profits to the firms from this consumer are as follows:

$$
\begin{gathered}
\pi_{P}^{*}=\left[1-z\left(p_{\mathrm{NP}}^{*}, \gamma\right)\right](1+h)=\frac{(1+h)(2-a+b \gamma)}{2} ; \\
\pi_{\mathrm{NP}}^{*}=p_{\mathrm{NP}}^{*} z\left(p_{\mathrm{NP}}^{*}, \gamma\right)=\frac{(a-b \gamma)^{2}}{4 b}
\end{gathered}
$$

If each consumer purchases from her preferred firm in the first period, the total profits of each firm from the two consumers in the second period are

$\pi^{*}=\pi_{P}^{*}+\pi_{\mathrm{NP}}^{*}=\frac{(2-a+b \gamma)(1+h)}{2}+\frac{(a-b \gamma)^{2}}{4 b}$

For this equilibrium to hold, two conditions must be satisfied. First, $p_{\mathrm{NP}}^{*}$ must be sufficiently low that it provides an incentive to each firm's resident consumer to potentially switch to the (nonpreferred) competitor. The consumer obtains zero utility from the preferred firm in this equilibrium - then the competitor should provide a (marginally) positive utility to this consumer. That is, $p_{\mathrm{NP}}^{*}$ $<1-\gamma$, which on simplification reduces to

$\gamma<\frac{2 b-a}{b}$

Second, the preferred firm should not have the incentive to undercut the competitor's price. Specifically, if the preferred firm offers a price that is marginally lower than $p_{\mathrm{NP}}^{*}+\gamma$ to its resident consumer, that consumer would never switch to the competitor. To ensure that the profits from such undercutting are lower than from pricing at $p_{P}^{*}=1+h$, the following must hold: $p_{\mathrm{NP}}^{*}+\gamma<[1-z(p-$ $\left.\left.\mathrm{NP}^{*}, \gamma\right)\right](1+h)$. On simplification, this yields

$\gamma<\frac{1-a-a h}{1-b-b h}-\frac{a-b-2 b h}{b-b^{2}-b^{2} h}$

Taking the first derivative of the total second-period profits given in Eq. 5 with respect to $\gamma$, the total single- period profits of each firm decrease with switching costs when

$\gamma<\frac{a-b-b h}{b}$

Therefore, for this equilibrium to hold and for the profits to be decreasing with switching cost, the following condition must hold:

$\gamma<\min \left\{\frac{2 b-a}{b}, \quad \frac{1-a-a h}{1-b-b h}-\frac{a-b-2 b h}{b-b^{2}-b^{2} h}, \frac{a-b-b h}{b}\right\}$

Commentary: This last finding is surprising because existing research views switching costs as generally contributing to increased profits in the short run. The rationale is that switching costs make the consumers more sticky to the firm they reside with or prefer, thereby reducing competition for those consumers. This helps the firm establish more of a local monopoly over those consumers, thereby decreasing market-level competition and increasing profits. However, this logic is only partially carried through in a customized pricing scenario. Indeed, as seen in Eq. 5, the profits from the firm's resident consumer do increase under customized pricing. However, an increase in switching costs makes each firm compete even more strongly to capture the competitor's resident consumer by offering a lower price to compensate for the increase in switching costs. When switching costs are sufficiently low (condition 8), the reduced profits from this more intense competition can negate the increased profits from the firm's resident consumer, leading to lower total profits. Further, the switching cost threshold in condition 8 increases with $a$ and decreases with $b$. Intuitively, when the likelihood that the consumer is willing to consider switching is higher, ceteris paribus, each firm is willing to compete for the competitor's consumer even when switching costs are relatively high.

Case 2: Firm $i$ is not the preferred firm of the consumer

A consumer who is not with the preferred firm always compares prices towards evaluating a switch back to the preferred firm. That is, $z=1$ for such a consumer. This consumer has a reservation price of 1 for the product of the firm she is currently with and $1+h$ for the preferred firm's product.

Sub-case 2.1: If $h \geq \gamma$, then the firm trying to retain the consumer will price at $p_{\mathrm{NP}}=0$ and the preferred firm trying to acquire the consumer will price $p_{P}=h-\gamma$ as it will need to account for switching costs. The consumer will switch to the preferred firm. The profits of the firm 
trying to retain the consumer, those of the firm trying to acquire the consumer, and the total profits of each firm in the second period given that each has a consumer in the first period are, respectively

$\pi_{\mathrm{NP}}^{*}=0 ; \quad \pi_{P}^{*}=h^{-\gamma} \quad \pi^{*}=h^{-\gamma}$

Sub-case 2.2: If $h<\gamma$, then the firm retaining the consumer will price at $p_{\mathrm{NP}}=\gamma-h$ because it can leverage the switching costs the consumer has to incur in moving to the preferred firm but has to account for the difference $h$ in reservation utility across the firms. The firm trying to acquire the consumer will price at $p_{P}=0$. The consumer will remain with the nonpreferred firm. The profits of the firm trying to retain the consumer, those of the firm trying to acquire the consumer, and the total profits of each firm in the second period given that each has a consumer in the first period are, respectively

$\pi_{\mathrm{NP}}^{*}=\gamma-h \quad \pi_{P}^{*}=0 \quad \pi^{*}=\gamma-h$

Commentary: The case where each firm begins with a consumer that does not prefer it has two deterministic outcomes because the consumer who is with a nonpreferred firm is always seeking an opportunity to switch. When the utility of being with the preferred firm is higher than the switching costs, switching always occurs to the preferred firm because even when the nonpreferred offers a price of zero, the consumer can gain additional utility by switching. In contrast, when the utility of being with the preferred firm is lower than the switching costs, the consumer does not find it worthwhile to switch to the preferred firm even if it offers a price of zero because the barrier posed by switching costs is too high.

\subsection{Two-Period Analysis}

Proceeding via backward induction, the single-period game solved above now constitutes the second period of the twoperiod game. Variables pertaining to the second period are denoted with the superscript " 2 ." We focus on four possible pure strategy equilibria ${ }^{4}$ corresponding to large and small $\gamma$ as represented by the inequalities 3,6 , and 7 above. Let $\delta(\delta=0,1)$ be the single-period discount factor to the consumers. When $\delta=0$, the consumers are myopic, and when $\delta=1$, the

\footnotetext{
${ }^{4}$ The parameter space where pure strategy equilibria exist does not overlap with the parameter space where mixed strategy equilibria exist. We focus only on the pure strategy equilibria region due to the ease of understanding such equilibria as compared to mixed strategy equilibria.
}

consumers are strategic. In each scenario, we compute and compare the implications of choosing the preferred or the nonpreferred firm in period 1 .

Scenario 1 Consider the scenario where $\gamma>\frac{1-a-a h}{1-b-b h}$ and $h \geq \gamma$, corresponding to a combination of sub-cases 1.1 and 2.1. If the consumer that prefers firm $i$ 's product buys from firm $i$ in period 1, then this consumer is retained by firm $i$ which charges a price of $h+\gamma$ to this consumer in period 2 (see sub-case 1.1 above). The consumer's expected surplus obtained from staying with the preferred firm in period 2 is (subscript S-P denotes "stay with preferred firm")

$S_{\text {S-P }}^{2}=1+h-p_{P}^{2}=1+h-(h+\gamma)=1-\gamma$

If the consumer that prefers firm $i$ 's product buys from the nonpreferred firm in period 1 , and if $h \geq \gamma$, this consumer will migrate to the preferred firm in period 2 (see sub-case 2.1 above). The expected surplus of this consumer in period 2 is (subscript M-P denotes "migrate to preferred firm")

$S_{\mathrm{M}-\mathrm{P}}^{2}=1+h-p_{P}^{2}-\gamma=1+h^{-}(h-\gamma)-\gamma=1$

The difference in expected period 2 surplus based on whether the consumer purchased from the preferred firm or not in period 1 is $k=S_{\mathrm{S}-\mathrm{P}}^{2}-S_{\mathrm{M}-\mathrm{P}}^{2}=-\gamma$. Consider the firm that is trying to attract the consumer who prefers the competitor. This firm, say firm 2, has zero profits from this consumer in period 2 irrespective of whether it succeeds in attracting the consumer. Therefore, the lowest price it will offer the consumer is $p_{\mathrm{NP}}^{1 *}=0$. It is then optimal for firm 1 to attract the same consumer by pricing at $p_{P}^{1 *}=p_{\mathrm{NP}}^{1 *}+h+\delta k=h-\delta \gamma$. Intuitively, firm 1 can charge a premium of $h$ over firm 2's price to account for its preferred status but also needs to lower the price by $(\delta \gamma)$ to account for the lower surplus it offers the consumer in period 2. The two-period profits of each firm from the consumer that prefers it and the one that does not are, respectively

$$
\begin{gathered}
\pi_{P}^{*}=p_{P}^{1 *}+\pi_{P}^{2 *}=h-\delta \gamma+(h+\gamma)=2 h+\gamma(1-\delta) \\
\pi_{\mathrm{NP}}^{*}=p_{\mathrm{NP}}^{1 *}+\pi_{\mathrm{NP}}^{2 *}=0
\end{gathered}
$$

The total two-period profits to each firm from both consumers are

$\pi^{*}=\pi_{P}^{*}+\pi_{\mathrm{NP}}^{*}=2 h+\gamma(1-\delta)$

These two-period profits are increasing in switching $\operatorname{costs}(\gamma)$. 
Scenario 2 Consider the scenario where $\gamma>\frac{1-a-a h}{1-b-b h}$ and $h<\gamma$, corresponding to a combination of sub-cases 1.1 and 2.2. If the consumer that prefers firm $i$ 's product buys from firm $i$ in period 1 , then, similar to scenario 1 and following sub-case 1.1 , this consumer's expected surplus in period 2 is $S_{\mathrm{S}-\mathrm{P}}^{2}=1$ $-\gamma$. If the consumer that prefers firm $i$ buys from the nonpreferred firm in period 1, following sub-case 2.2, the expected surplus of this consumer in period 2 is (subscript S-NP denotes "stay with nonpreferred firm")

$S_{\mathrm{S}-\mathrm{NP}}^{2}=1-p_{\mathrm{NP}}^{2}=1-(\gamma-h)$

Therefore, the difference in surplus is $k=S_{\mathrm{S}-\mathrm{P}}^{2}-S_{\mathrm{S}-\mathrm{NP}}^{2}=-h$. Now, in period 1 , consider the firm that is trying to attract the consumer who prefers the competitor. This firm, say firm 2 , has profits of $\gamma-h$ from this consumer in period 2 if it succeeds in attracting the consumer in period 1 and has zero profit in the second period if otherwise (see sub-cases 1.1 and 2.2). Therefore, to attract this consumer in period 1, this firm will be willing to invest, at most, all its expected period 2 profits from the consumer-therefore, the lowest price it will offer the consumer is $p_{\mathrm{NP}}^{1 *}=-(\gamma-h)=h-\gamma$. Firm 1 will attract the same consumer by offering a price of $p_{P}^{1 *}=p_{\mathrm{NP}}^{1 *}+h+\delta k=(2$ $-\delta) h-\gamma$. Intuitively, firm 1 can charge a premium of $h$ over firm 2's price to account for its preferred status but also needs to adjust the price by $(\delta k)$ to account for the lower surplus it offers the consumer in period 2. By charging this price, firm 1 ensures that it attracts the consumer that prefers it. It is also easy to verify that firm 1 will be worse off if it chooses not to attract the consumer by pricing higher than $p_{P}^{1 *}$.

The two-period profits of each firm from the consumer that prefers it, from the consumer that does not prefer it, and from both consumers are, respectively

$$
\begin{aligned}
\pi_{P}^{*} & =p_{P}^{1 *}+\pi_{P}^{2 *}=(2-\delta) h-\gamma+(h+\gamma) \\
& =(3-\delta) h ; \pi_{\mathrm{NP}}^{*}=0 ; \pi^{*}=(3-\delta) h
\end{aligned}
$$

Commentary: Switching costs play a conventional, anticompetitive role in scenario 1, and the profits of each firm increase with switching costs. In this scenario, switching costs are responsible for keeping the consumer with his or her preferred firm across both periods - there is no switching in equilibrium. The greater the switching costs, the greater the surplus the firm can extract from its preferred consumer without risking consumer defection. In scenario 2, likewise, there is no switching in equilibrium and each consumer purchases from his or her preferred firm in both periods. However, the total two-period profits of each firm are independent of switching $\operatorname{cost} \gamma$. The intuition is as follows. When $h<\gamma$, i.e., the benefits of patronizing the preferred firm are lower than switching costs, it is particularly important for each firm to capture its preferred consumer in period 1 because a consumer who chooses a nonpreferred firm in period 1 will continue to patronize that firm in period 2. Each firm therefore lowers its price to the consumer that prefers it in period 1 to the extent that the firm competes away the profit-generating potential of the switching costs in period 2 in order to price sufficiently below the competitor.

Scenario 3 Consider the scenario where $\gamma<\min$ $\left\{\frac{2 b-a}{b}, \frac{1-a-a h}{1-b-b h}-\frac{a-b-2 b h}{b-b^{2}-b^{2} h}\right\}$ and $h \geq \gamma$. This corresponds to a combination of sub-cases 1.2 and 2.1. We first compute the expected surplus in period 2 of the consumer that patronizes her preferred firm $i$ in period 1. Following sub-case 1.2, this firm prices at $p_{P}^{2 *}=1+h$ to its preferred consumer, who remains with it with probability $1-z\left(p_{\mathrm{NP}}^{*}, \gamma\right)=1-\frac{a-b \gamma}{2}$ and receives zero surplus. With probability $z\left(p_{\mathrm{NP}}^{2 *}, \gamma\right)=\frac{a-b \gamma}{2}$, this consumer compares prices across firms and will switch to the nonpreferred firm that offers a price of $p_{\mathrm{NP}}^{2 *}=\frac{a-b \gamma}{2 b}$. The associated surplus is

$$
\begin{aligned}
& S_{\mathrm{S}-\mathrm{NP}}^{2 *}=z\left(p_{\mathrm{NP}}^{2 *}, \gamma\right)\left(1-p_{\mathrm{NP}}^{2 *}-\gamma\right)=\frac{a-b \gamma}{2}\left(1-\frac{a-b \gamma}{2 b}-\gamma\right) \\
& \quad=\frac{a-b \gamma}{2}-\frac{a^{2}-b^{2} \gamma^{2}}{4 b}
\end{aligned}
$$

Next, consider the case where the consumer that prefers firm $i$ 's product buys from the competitor in period 1 . As seen in sub-case 2.1, this consumer will switch to the preferred firm in period 2 when $h \geq \gamma$, obtaining a period 2 surplus of $S_{\mathrm{M}-\mathrm{P}}^{2 *}=1$ (Eq. 13). The surplus gap is $k=S_{\mathrm{S}-\mathrm{NP}}^{2 *}-S_{\mathrm{M}-\mathrm{P}}^{2 *}=\frac{a-b \gamma}{2}-\frac{a^{2}-b^{2} \gamma^{2}}{4 b}-1$ . Here, $k<0$ because $z\left(p_{\mathrm{NP}}^{2 *}, \gamma\right)<1$ and $\left(1-p_{\mathrm{NP}}^{2^{*}}-\gamma\right)<1$ in Eq. 18 .

Consider the (strategic) nonpreferred firm. This firm earns profits of $\pi_{\mathrm{NP}}^{2 *}=0$ from the consumer that does not prefer it in period 2 if it obtains that consumer in period 1 (see sub-case 2.1 above); it earns profits of $\pi_{\mathrm{NP}}^{2 *}=\frac{(a-b \gamma)^{2}}{4 b}$ in period 2 if it loses the consumer in period 1 (sub-case 1.2 above). Therefore, its price in period 1 is the difference between the two possible period 2 profit levels:

$p_{\mathrm{NP}}^{1 *}=\frac{(a-b \gamma)^{2}}{4 b}-0=\frac{(a-b \gamma)^{2}}{4 b}$

This price is positive because the firm recognizes that it can earn higher profits in period 2 if it does not capture the consumer in period 1 -this prevents the price from dropping 
further. In contrast, if the firm is nonstrategic, it will set $p_{\mathrm{NP}}^{1 *}=0$ in period 1 . The firm that is preferred by the consumer will price her optimally at

$$
\begin{aligned}
p_{P}^{1 *}= & p_{\mathrm{NP}}^{1 *}+h+\delta k=\frac{(a-b \gamma)^{2}}{4 b} \\
& +h+\delta\left(\frac{a-b \gamma}{2}-\frac{a^{2}-b^{2} \gamma^{2}}{4 b}-1\right)
\end{aligned}
$$

The two-period profits of each firm from the consumer that prefers it, from the consumer that does not prefer it, and from both consumers are, respectively (referring to Eqs. 4 and 5)

$$
\begin{aligned}
\pi_{P}^{*} & =p_{P}^{1 *}+\pi_{P}^{2 *}=\frac{(a-b \gamma)^{2}}{4 b}+h+\delta\left(\frac{a-b \gamma}{2}-\frac{a^{2}-b^{2} \gamma^{2}}{4 b}-1\right) \\
& +\frac{2-a+b \gamma}{2}(1+h) \pi_{\mathrm{NP}}^{*}=\frac{(a-b \gamma)^{2}}{4 b} \pi^{*}=\pi_{P}^{*}+\pi_{\mathrm{NP}}^{*} \\
& =\frac{(a-b \gamma)^{2}}{2 b}+h+\delta\left(\frac{a-b \gamma}{2}-\frac{a^{2}-b^{2} \gamma^{2}}{4 b}-1\right)+\frac{2-a+b \gamma}{2}(1+h)
\end{aligned}
$$

For total profits to decrease with switching cost, the following condition must hold:

$$
\frac{\partial \pi^{*}}{\partial \gamma}<0 \Rightarrow-(a-b \gamma)-\delta b(1-\gamma)+[b(1+h)-(a-b \gamma)]<0
$$

If condition 8 holds, i.e., $[b(1+h)-(a-b \gamma)]<0$, then condition 22 also holds. In that case, both the period 1 and 2 profits of each firm decrease with switching cost $\gamma$.

Scenario 4 Consider the scenario where $\gamma<\min$ $\left\{\frac{2 b-a}{b}, \frac{1-a-a h}{1-b-b h}-\frac{a-b-2 b h}{b-b^{2}-b^{2} h}\right\}$ and $h<\gamma$, corresponding to a combination of sub-cases 1.2 and 2.2. If the consumer that prefers firm $i$ 's product buys from firm $i$ in period 1, then, from Eq. 20, this consumer's expected period 2 surplus is $\left(\frac{a-b \gamma}{2}-\frac{a^{2}-b^{2} \gamma^{2}}{4 b}\right)$. If the consumer that prefers firm $i$ 's product buys from its competitor in period $1(z=1)$, the consumer remains with the nonpreferred firm in period 2 and obtains a surplus of $1-(\gamma-h)$ (from Eq. 16). Therefore, the difference in surplus is

$k=\left(\frac{a-b \gamma}{2}-\frac{a^{2}-b^{2} \gamma^{2}}{4 b}\right)-[1-(\gamma-h)]$
Note that $k<0$ because $z\left(p_{\mathrm{NP}}^{2 *}, \gamma\right)<1$ and $\left(1-p_{\mathrm{NP}}^{2^{*}}-\gamma\right)<1-\gamma+$ $h$. Therefore, the consumer obtains a higher surplus from remaining with the nonpreferred firm in period 2 .

Consider the nonpreferred firm. From the consumer that does not prefer it, this firm earns profits of $\pi_{\mathrm{NP}}^{2^{*}}=\gamma-h$ in period 2 if it obtains that consumer in period 1 (see sub-case 2.2); it earns profits of $\pi_{\mathrm{NP}}^{2 *}=\frac{(a-b \gamma)^{2}}{4 b}$ in period 2 if it does not (subcase 1.2 above). Therefore, its price in the first period to the consumer that does not prefer it is the difference between the two possible second-period profit levels:

$p_{\mathrm{NP}}^{1 *}=\frac{(a-b \gamma)^{2}}{4 b}-(\gamma-h)$

The firm that is preferred by the consumer will optimally price to that consumer at

$p_{P}^{1 *}=p_{\mathrm{NP}}^{1 *}+h+\delta k$

and will obtain the consumer. Therefore, the firm's total twoperiod profits from that consumer are

$\pi_{P}^{*}=\frac{(a-b \gamma)^{2}}{4 b}-(\gamma-h)+h+\delta k+\frac{(1+h)(2-a+b \gamma)}{2}$

The total two-period profits of a firm from the consumer that does not prefer it are (from Eq. 2)

$\pi_{\mathrm{NP}}^{*}=\frac{(a-b \gamma)^{2}}{4 b}$

Therefore, the total profits of each firm are (adding Eqs. 26 and 27)

$\pi^{*}=\frac{(a-b \gamma)^{2}}{2 b}-(\gamma-h)+h+\delta k+\frac{(1+h)(2-a+b \gamma)}{2}$

For these profits to decrease with switching costs,

$$
\begin{aligned}
\frac{\partial \pi^{*}}{\partial \gamma}< & 0 \Rightarrow-(a-b \gamma)-\delta b(1-\gamma)-(1-\delta) \\
& +[b(1+h)-(a-b \gamma)]<0
\end{aligned}
$$

If condition 8 above holds, i.e., $[b(1+h)-(a-b \gamma)]<0$, then condition 29 also holds. In that case, both the period 1 and 2 profits of each firm decrease with switching costs $(\gamma)$. 
Commentary: An interesting aspect of scenario 3 is that each firm would prefer not to obtain the consumer that does not prefer it in period 1. Intuitively, if a consumer begins with a nonpreferred firm in period 1 , that consumer will always switch to the competitor under sub-case 2.1 yielding zero profit for the nonpreferred firm in period 2 . In contrast, if that consumer patronized the preferred firm in period 1 , there is a positive likelihood of the nonpreferred firm obtaining positive profits from the consumer in period 2. This is because under sub-case 1.2 , the firm prices to its preferred consumer at $p_{P}^{2 *}=1+h$, a price that extracts all surplus from that consumer. In response, the competitor can price at a level that maximizes expected profits after taking into account how the chosen price affects both the margin and the likelihood that the nonpreferred consumer evaluates switching (see Eq. 4). In contrast, under scenario 4, a firm will retain consumer that does not prefer it if it is able to capture that consumer in period 1 because the switching costs are high compared to the additional utility associated with the preferred firm (i.e., $h<\gamma$ under sub-case 2.2).

Under scenarios 3 and 4, each firm's two-period profits from the consumer that does not prefer it decrease with switching cost (Eqs. 21 and 27). However, the total twoperiod profits of each firm can either increase or decrease with switching costs. Specifically, Eqs. 22 and 29 indicate that, in each scenario, total firm profits decrease (increase) with switching costs when magnitude of this cost is low (high). Further, when the switching cost is sufficiently low, both period 1 and period 2 profits decrease with switching costs (see inequality 8).

These findings depart from the literature. In existing models, short-term (single-period) profits generally increase with switching cost, and the debate is focused on whether and when this results in increasing long-term profits. However, in a customized pricing scenario, we demonstrate that even single-period profits can decrease with switching cost. This indicates that switching costs can exert a pro-competitive influence even in the short run.

Shin and Sudhir [4] demonstrate that total two-period profits decrease (increase) with switching costs when those costs are low (high). Our findings can be differentiated as follows. First, unlike their model which features a single price from each firm, we examine a customized pricing scenario where firms discriminate between consumer types. Second, the consumers in their model are myopic - those in our model are strategic. Third, consumers in their model have shifting preferences across periods, with preferences in each period being drawn from a random distribution. In contrast, our findings hold even with stable preferences. Further, unlike Cabral [22], in our model, no asymmetries related to market share are required for switching costs to exert an anti- competitive effect. Our work complements $[4,21,22]$ by examining the strategic implications of switching costs in a customized pricing scenario.

Our findings also counter the view in the literature that firm profits under switching increase when consumers are strategic. The traditional intuition is that strategic consumers are conscious about being locked-in by high switching costs, allowing the firm to charge high prices and extract surplus in the future. Accordingly, they are less likely to be sensitive to low price baits offered during the early stages of competition. This reduced price sensitivity moderates competition and increases profits. In contrast, in our model, the difference in surplus $k$ is negative in all four scenarios, indicating that firm profits are lower when consumers are strategic. Intuitively, to acquire consumers, firms choose to price even lower to compensate strategic consumers for the loss of future surplus. This reduces total firm profits compared to the case where consumers are myopic. ${ }^{5}$

Finally, in a technical context, we prove that there is a feasible space in parameters $a, b$, and $h$ such that there will be a unique equilibrium where total profits of each firm decrease with $\gamma$ (see Appendix).

\section{Conclusion}

The existing literature on switching costs in marketing and economics has focused on market-level pricing. In contrast, we analyze the strategic influence of switching costs when duopolists engage in customized pricing. In addition, reflecting the cluttered marketing environment and the limited attention span of modern consumers, we endogenize the probability that the consumer will fully evaluate the costs and benefits of switching to a nonpreferred firm as a decreasing function of the price offered by that firm. Our analysis delivers insights that complement, and sometimes challenge, existing findings.

First, we demonstrate that increasing switching costs can decrease profits even when firms compete within a single period. Moving to multi-period competition, we demarcate zones where single-period and total (long-run) profits can decrease or increase with switching costs under customized pricing. Finally, whereas the literature suggests that firm profits in competitive environments increase in the presence of strategic consumers, we demonstrate that the opposite effect may hold.

From a research viewpoint, our findings suggest that the strategic implications of switching costs are quite different

\footnotetext{
${ }^{5}$ For an analysis of how short-term, period-by-period profit maximization may yield higher profits than multi-period profit maximization, see Villanueva et al. [35].
} 
under customized and market-level pricing. Our findings also highlight the importance of contextual factors in influencing how the actions of firms ultimately affect the nature of competition and profitability. As demonstrated in the analysis, the nature of competition and the corresponding equilibrium outcomes vary as a function of the specific parametric configurations that capture distinct market realities. This suggests that fine-grained, context-specific theorization regarding switching costs is more likely to yield correct, useful, and usable insights than broad generalizations about their effects.

From a managerial viewpoint, our findings provide some new insights into the management of switching costs. Managers frequently seek to build long-term consumer relationships by investing in loyalty programs that increase switching costs. However, our findings suggest that managers must carefully consider the strategic implications of these programs. Such initiatives may sharpen competitive reactions and lower profits, even in situations where firms can target consumers that prefer them and those that prefer a competitor with separate prices. Likewise, managers may assume that strategic consumers may increase profits because they are less price sensitive at the early stages of competition. Our findings suggest that managers must first carefully consider the nature of the competitive regime. Making consumers more strategic can actually decrease profits because the competitor may decide to price even more aggressively upfront in order to compensate them for the surplus they would now expect to lose in the future.

Finally, our findings offer an explanation for some recent initiatives of firms to reduce switching costs. Cellular service providers in the telecom industry are discarding the strategy of selling cell phones that are locked into their network. Companies like AT\&T and Verizon now even operate websites and offer seminars that provide advice on achieving interoperability between devices that were earlier tightly constrained to work within specific networks [36]. These initiatives reduce switching costs-however, consistent with our model, they could arguably also reduce competition for consumers and increase profitability.

Moving forward, two research issues deserve attention. First, instead of focusing solely on profit maximization, firms may seek to balance long-term profit with more short-term objectives related to market share. The implications of switching costs can be studied in these settings. Second, the implications of switching costs for choice could be explored more deeply from a behavioral perspective. Specifically, when do consumers consider switching costs to be an acceptable barrier to switching as opposed to an unreasonable constraint that reduces satisfaction with the firm? Insights into this issue would allow managers to focus on building the "right" kind of switching costs that promote consumer loyalty and profitability.

\section{Appendix}

We now show that there is a feasible space in parameters $a, b$, and $h$ such that there will be a unique equilibrium where the total profits of each firm decreases with $\gamma$. The sufficient conditions for such a feasible region of $a, b$, and $h$ are

(a) From the assumption that $0 \leq z \leq 1$ for all $0 \leq \gamma \leq 1, a \geq b$.

(b) For condition 9 to hold requires

$$
\begin{aligned}
& \gamma<\min \left\{\frac{2 b-a}{b}, \quad \frac{1-a-a h}{1-b-b h}-\frac{a-b-2 b h}{b-b^{2}-b^{2} h}, \frac{a-b-b h}{b}\right\} \\
& \min \left\{\frac{2 b-a}{b}, \quad \frac{1-a-a h}{1-b-b h}-\frac{a-b-2 b h}{b-b^{2}-b^{2} h}, \frac{a-b-b h}{b}\right\}>0
\end{aligned}
$$

(c) For regions defined by condition 3 on the one hand, and conditions 6 and 7 on the other to be nonoverlapping, that is, for the pure strategy equilibrium to be unique we also need:

$$
\frac{1-a-a h}{1-b-b h}>\min \left\{\frac{2 b-a}{b}, \quad \frac{1-a-a h}{1-b-b h}-\frac{a-b-2 b h}{b-b^{2}-b^{2} h}\right\}
$$

For condition (b) above to hold, we need

(i) $\frac{2 b-a}{b}>0 \Rightarrow b>\frac{a}{2}$. From (a) above and this condition, we obtain $\frac{a}{2}<b \leq a$.

(ii)

$$
\frac{a-b-b h}{b}>0 \Rightarrow 1+h<\frac{a}{b}
$$

(iii) $\frac{1-a-a h}{1-b-b h} \frac{a-b-2 b h}{b-b^{2}-b^{2} h}>0 \Rightarrow \frac{b(1-a-a h)-(a-b-2 b h)}{b(1-b-b h)}>0$. For the condition 3 to ever hold, we need $(1-b-b h)>0$ or $1+h<\frac{1}{b}$. This is because if $(1-b-b h)<0$, then given that $a \leq 1$, (ii) cannot hold. If $(1-b-b h)>0$, then for $\frac{b(1-a-a h)-(a-b-2 b h)}{b(1-b-b h)}>0$, it must be that $(1+h)>$ $\frac{a}{(2-a) b}$. For condition (c) to hold, a necessary condition is that $\frac{1-a-a h}{1-b-b h}>0$, which requires that $1-a-a h>0 \Rightarrow$ $(1+h)<\frac{1}{a}$.

For $\frac{1-a-a h}{1-b-b h}>\min \left(\frac{2 b-a}{b}, \quad \frac{1-a-a h}{1-b-b h}-\frac{a-b-2 b h}{b-b^{2}-b^{2} h}\right), \frac{1-a-a h}{1-b-b h}>\frac{2 b-a}{b} \Rightarrow$ $1+h<\frac{1}{2 b}$. Also, $\frac{a-b-2 b h}{b-b^{2}-b^{2} h}>0 \Rightarrow a-b-2 b h>0 \Rightarrow 1+h<\frac{a+b}{2 b}$.

Therefore, the conditions that we now have are $\frac{a}{2}<b \leq a$, $1+h<\frac{a}{b}, 1+h<\frac{1}{a}, 1+h<\frac{1}{b}, 1+h<\frac{1}{2 b}$, $1+h<\frac{a+b}{2 b}$, and $1+h>\frac{a}{(2-a) b}$. Because $\frac{a}{2}<b$, we have 
$1+h<\frac{1}{2 b} \Rightarrow 1+h<\frac{1}{a}$. Because $b \leq a$, we have $1+h<\frac{a+b}{2 b}$ $\Rightarrow 1+h<\frac{a}{b}$. Thus, the above conditions reduce to $\frac{a}{2}<b \leq a$ and $\min \left(\frac{1}{2 b}, \frac{a+b}{2 b}\right)>(1+h)>\frac{a}{(2-a) b}$. Therefore, we require that $\min \left(\frac{1}{2 b}, \frac{a+b}{2 b}\right)>\frac{a}{(2-a) b}$. For $\frac{1}{2 b}>\frac{a}{(2-a) b}, a<\frac{2}{3}$. For $\frac{a+b}{2 b}>$ $\frac{a}{(2-a) b}, b>\frac{a^{2}}{2-a}$. We also have $b>\frac{a}{2}>\frac{a^{2}}{2-a}$ when $a<\frac{2}{3}$. So, $\min \left(\frac{1}{2 b}, \frac{a+b}{2 b}\right)>\frac{a}{(2-a) b}$ implies $a<\frac{2}{3}$. As $\frac{a+b}{2 b}=\frac{a}{2 b}+\frac{1}{2}$ and $\frac{a}{2}<b$, we have $\frac{a+b}{2 b}<\frac{3}{2}$. Thus, $\max \left[\min \left(\frac{1}{2 b}, \frac{a+b}{2 b}\right)\right]=\frac{3}{2}$. Therefore, $\frac{3}{2}>1+h \Rightarrow h<\frac{1}{2}$.

This implies that, for any $0 \leq h<\frac{1}{2}$, we can find some feasible values of $(a, b)$, such that $a<\frac{2}{3}$ and $\frac{a}{2}<b \leq a$ to satisfy the conditions (a)-(c) above.

\section{References}

1. Klemperer P (1987) The competitiveness of markets with switching costs. RAND J Econ 18:138-150

2. Klemperer P (1989) Price wars caused by switching costs. Rev Econ Stud 56:405-420

3. Lam SY, Shankar V, Erramilli MK, Murthy B (2004) Customer value, satisfaction, loyalty, and switching costs: an illustration from a business-to-business service context. J Acad Mark Sci 32:293-311

4. Shin J, Sudhir K (2009) Switching costs and market competitiveness: deconstructing the relationship. J Mark Res XLVI:446-449

5. Shilony Y (1977) Mixed pricing in oligopoly. J Econ Theory 14:373388

6. Padilla AJ (1995) Revisiting dynamic duopoly with consumer switching costs. J Econ Theory 67:520-530

7. Taylor CR (2003) Supplier surfing: competition and consumer behavior in subscription markets. RAND J Econ 34:223-246

8. von Weizsacker CC (1984) The costs of substitution. Econometrica 52:1085-1116

9. Klemperer P (1987) Markets with consumer switching costs. Q J Econ 102:375-394

10. Klemperer P (1987) Entry deterrence in markets with consumer switching costs. Econ J 97:99-117, Supplement: Conference papers

11. Shi M, Chiang J, Rhee B (2006) Price competition with reduced consumer switching costs: the case of "Wireless Number Portability" as in the published article. Manag Sci 52:27-38

12. Fudenberg D, Villas-Boas M (2006) Behavior-based price discrimination and customer recognition. In: Hendershott TJ (ed) Handbook on economics and information systems. Elsevier, Amsterdam

13. Farrell J, Shapiro C (1988) Dynamic competition with switching costs. RAND J Econ 19:123-137
14. Padilla AJ (1992) Mixed pricing in oligopoly with consumer switching costs. Int J Ind Organ 10:393-412

15. Villas-Boas JM (1999) Dynamic competition with customer recognition. RAND J Econ 30:604-631

16. Villas-Boas JM (2004) Price cycles in markets with customer recognition. RAND J Econ 35:486-501

17. Kim B, Shi M, Srinivasan K (2001) Reward programs and tacit collusion. Mark Sci 20:99-120

18. Narasimhan C (1988) Competitive promotional strategies. J Bus 61:427-449

19. Raju JS, Srinivasan V, Lal R (1990) The effects of brand loyalty on competitive price promotional strategies. Manag Sci 36:276-304

20. Chen Y, Pearcy J (2010) Dynamic pricing: when to entice brand switching and when to reward consumer loyalty. RAND J Econ 41:674-685

21. Dubé J-P, Hitsch G, Rossi PE (2009) Do switching costs make markets less competitive? J Mark Res XLVI:435-445

22. Cabral L (2009) Small switching costs lead to lower prices. J Mark Res XLVI:449-451

23. Shaffer G, Zhang ZJ (1995) Competitive coupon targeting. Mark Sci $14: 395-416$

24. Chen Y (1997) Paying customers to switch. J Econ Manag Strateg 6: 877-897

25. Fudenberg D, Tirole J (2000) Customer poaching and brand switching. RAND J Econ 31:634-657

26. Chen Y, Iyer G (2002) Consumer addressability and customized pricing. Mark Sci 21:197-208

27. Chen Y, Narasimhan C, Zhang ZJ (2001) Individual marketing with imperfect targetability. Mark Sci 20:23-41

28. Shaffer G, Zhang ZJ (2002) Competitive one-to-one promotions. Manag Sci 48:1143-1160

29. Singh SS, Jain DC, Krishnan TV (2008) Customer loyalty programs: are they profitable? Manag Sci 54:1205-1211

30. Pancras J, Sudhir K (2007) Optimal Marketing Strategies for a Customer Data Intermediary. Journal of Marketing Research, 44:4, $560-578$

31. Hotelling H (1929) Stability in competition. Econ J 39:41-57

32. Kahneman D (1973) Attention and effort. Prentice-Hall, Englewood Cliffs

33. Marcel AJ (1983) Conscious and unconscious perception: an approach to the relations between phenomenal experience and perceptual processes. Cogn Psychol 15:238-300

34. Shiffrin RM, Schneider W (1977) Controlled and automatic human information processing: II. Perceptual learning, automatic attending, and a general theory. Psychol Rev 84:127-190

35. Villanueva J, Bhardwaj P, Balasubramanian S, Chen Y (2007) Customer relationship management in competitive environments: the positive implications of a short-term focus. Quant Mark Econ 5:99-129

36. Johnson CY (2008) Big wireless carriers get set to free the phone. Boston Globe. Accessed 1 Apr 2008: www.boston.com/business/ technology/articles/2008/03/28/big_wireless_carriers_get_set_to_ free the phone/ 